\title{
National Trends in Primary Care Visit Use and Practice Capabilities, 2008-2015
}

Aarti Rao, $B A^{1}$

Zbuo Sbi, BA ${ }^{2}$

Kristin N. Ray, MD, $M S^{3}$

Ateev Mebrotra, MD, $M P H^{2,4}$

Ishani Ganguli, $M D, M P H^{2,5}$

'Icahn School of Medicine at Mount Sinai, New York City, New York

${ }^{2}$ Harvard Medical School, Boston, Massachusetts

${ }^{3}$ Department of Pediatrics, University of Pittsburgh School of Medicine, Pittsburgh, Pennsylvania

${ }^{4}$ Division of General Medicine and Primary Care, Beth Israel Deaconess Medical

Center, Boston, Massachusetts

${ }^{5}$ Division of General Internal Medicine and Primary Care, Brigham and Women's Hospital, Boston, Massachusetts

Conflicts of interest: Dr Ganguli reports receiving compensation as a consultant from Haven. The authors bave no other conflicts of interest to disclose.

\section{CORRESPONDING AUTHOR}

Ishani Ganguli, MD, MPH

Brigham and Women's Hospital, Division of General Internal Medicine and Primary Care

1620 Tremont Street, 3rd Floor

Boston, MA 02120

iganguli@bwh.harvard.edu

\begin{abstract}
PURPOSE Recent evidence shows a national decline in primary care visit rates over the last decade. It is unclear how changes in practice-including the use and content of primary care visits - may have contributed.
\end{abstract}

METHODS We analyzed nationally representative data of adult visits to primary care physicians (PCPs) and physician practice characteristics from 2007-2016 (National Ambulatory Medical Care Survey). United States census estimates were used to calculate visits per capita. Measures included visit rates per person year; visit duration; number of medications, diagnoses, and preventive services per visit; percentage of visits with scheduled follow-up; and percentage of physicians with practice capabilities including an electronic medical record (EMR).

RESULTS Our weighted sample represented 3.2 billion visits (83,368 visits, unweighted). Visits per capita declined by $20 \%$ ( -0.25 visits per person, $95 \% \mathrm{Cl}$, -0.32 to -0.19 ) during this time, while visit duration increased by 2.4 minutes per visit $(95 \% \mathrm{Cl}, 1.1-3.8)$. Per visit, PCPs addressed 0.30 more diagnoses $(95 \%$ $\mathrm{Cl}, 0.16-0.43)$ and 0.82 more medications $(95 \% \mathrm{Cl}, 0.59-1.1)$, and provided 0.24 more preventive services $(95 \% \mathrm{Cl}, 0.12-0.36)$. Visits with scheduled PCP followup declined by $6.0 \%\left(95 \% \mathrm{Cl}_{1}-12.4\right.$ to 0.46$)$, while PCPs reporting use of EMR increased by $44.3 \%(95 \% \mathrm{Cl}, 39.1-49.5)$ and those reporting use of secure messaging increased by $60.9 \%(95 \% \mathrm{Cl}, 27.5-94.3)$.

CONCLUSION From 2008 to 2015, primary care visits were longer, addressed more issues per visit, and were less likely to have scheduled follow-up for certain patients and conditions. Meanwhile, more PCPs offered non-face-to-face care. The decline in primary care visit rates may be explained in part by PCPs offering more comprehensive in-person visits and using more non-face-to-face care.

Ann Fam Med 2019;17:538-544. https://doi.org/10.1370/afm.2474.

\section{INTRODUCTION}

$\mathrm{P}$ rimary care is an essential component of a high-performing health care system. ${ }^{1}$ Patients with access to a regular primary care physician (PCP) are more likely to receive recommended screenings, have fewer preventable hospital admissions, and experience lower mortality. ${ }^{2-4}$ In kind, many US policy initiatives over the past decade have sought to bolster primary care use and access. For example, the Patient Protection and Affordable Care Act eliminated co-payments for recommended preventive services and introduced the Annual Wellness Visit for Medicare patients. ${ }^{5}$ Yet, there is recent evidence of a $6 \%-25 \%$ decline in primary care visit rates over the past decade across commercial, Medicare, and nationally representative samples ${ }^{6-8}$ and it is unclear why.

Among other mechanisms, the decline may be explained in part by changes in how physicians provide primary care both during and outside of in-person visits. ${ }^{8}$ For example, aided by electronic health records, ${ }^{9,10}$ PCPs may be able to address more issues during a given in-person visit. ${ }^{11,12} \mathrm{~W}$ ith the encouragement of initiatives like the 2009 Health Information Technology for Economic and Clinical Health Act $(\mathrm{HITECH})^{13}$ and the patient centered medical home model, ${ }^{14} \mathrm{PCPs}$ may 
also provide more non-face-to-face care outside of those visits (eg, through secure messaging or virtual visits). ${ }^{15,16}$ Yet, there is little evidence of how the use and content of primary care visits and physician practice capabilities have changed in this context over the past decade. ${ }^{17}$

Understanding the potential contribution of primary care practice changes to a decline in visit rates may help policy makers and health care leaders make sense of and respond to this trend. Therefore, we assessed national trends in primary care visits and practice capabilities using 2007-2016 data from the National Ambulatory Medical Care Survey (NAMCS).

\section{METHODS}

\section{Data Sources}

We used NAMCS data from January 1, 2007 to December 31,2016 . NAMCS is a nationally representative survey conducted annually by the National Center for Health Statistics (NCHS) to examine patient visits to physicians in non-federally funded, non-hospital-based offices.

Through a standardized form completed by a physician or an outside coder using the medical record, NAMCS collects visit-level data on patient demographic information and clinical details, such as the main visit diagnoses, services provided, and visit disposition. NAMCS also collects physician and practicelevel data through a physician induction survey.

NAMCS uses a 3-stage stratified sampling design that allows for calculation of national estimates at the visit and physician level. The first stage sample includes 112 primary sampling units consisting of geographic segments (eg, counties and towns) within the United States. The second stage sample consists of practicing physicians selected from the American Medical Association Masterfile. Lastly, for each physician practice selected, visits are sampled during a randomly selected 1-week period.

We obtained 2007-2016 data on the total US population as well as the age, sex, race, insurance status, and setting of US adults from the Current Population Survey (CPS).

\section{Study Sample}

We examined ambulatory visits to physicians by patients aged $\geq 18$ years. We identified primary care visits as those performed by a physician with a selfreported specialty of internal medicine, pediatrics, or family medicine. We excluded community health center visits to allow for consistency across the study period as recommended by the NCHS.

\section{Measures}

For each visit, we described patient characteristics (age, sex, race, insurance status, setting) and the primary visit diagnosis or patient reason for visit (Supplemental Tables 1 and 2, http://www.AnnFamMed.org/ content/17/6/538/suppl/DC1). To further examine visit content, we determined the number of visit diagnoses (up to 3 listed International Classification of Diseases, Ninth Revision [ICD-9]/International Classification of Diseases, Tenth Revision [ICD-10] codes), medications (up to 8 per visit), preventive services (up to 9 per visit out of the following services included in NAMCS 2007-2016: cholesterol, hemoglobin $\mathrm{A}_{1 \mathrm{c}}$, mammogram, depression screening, colonoscopy referral, bonedensity, vaccines, chlamydia screening, and Papanicolaou smear), and procedures (up to 4 per visit out of the following 8 procedures commonly performed by PCPs: ultrasound, wound care, skin excision, infusion, biopsy, irrigation, joint care, cerumen removal) (Supplemental Table 3, http://www.AnnFamMed.org/content/17/6/538/ suppl/DC1). We also assessed visit duration (physicianreported time directly spent with each patient), and whether the visit was associated with scheduled follow-up. To assess PCP use of non-face-to-face and after-hours care, we examined the following physicianlevel capabilities that were consistently included in the survey instrument during the study period: electronic medical record (EMR), e-mail consultation, electronic messaging (data available 2011-2015), telephone consultation, and after-hours appointments.

\section{Analysis}

We calculated visits per capita by dividing the number of visits by the annual CPS population estimate overall and for each demographic subgroup. We also calculated per capita visit rates by their primary visit diagnosis groups. In each year, we estimated mean visit duration and mean number of diagnoses, medications, preventive services, and procedures per visit. In a sensitivity analysis to address the possibility that changes in the number of diagnoses and medications addressed per visit may be confounded by the adoption of electronic medical records, we stratified trends in diagnoses and medications per visit by practice EMR capability. We examined trends in visits with scheduled in-person PCP follow-up over time by estimating the percentage of visits each year with a scheduled follow-up overall and by patient characteristics and visit diagnosis groups. To identify trends in practice capabilities, we used physician-level weights to estimate the percentage of physicians who reported having a given practice capability in each year.

We used 3-year rolling averages to minimize yearly fluctuations (eg, 2008 estimate included 2007-2009 
data) throughout the analysis. We tested for trends over time using either survey-weighted linear regressions (continuous variables) or linear proportion models (dichotomous variables) with year (grouped into 3-year rolling averages) as a continuous independent variable and presented results as the change across 8 years. In accordance with NCHS standards, we excluded estimates with fewer than 30 unweighted cases per cell. ${ }^{18}$ We used Stata version 14.1 (StataCorp LLC) to perform all analyses. This study of de-identified survey data was exempt from review based on 45CFR46.102.

\section{RESULTS}

Over the 8-year period, our weighted sample represented 3.2 billion primary care visits. The number of primary care visits decreased from 336 million to 299 million per year. Per capita visit rates declined from 1.5 visits per person in 2008 to 1.2 visits per person in 2015: a $20 \%$ decline over the study period $(-0.25$ visits per person, $95 \% \mathrm{CI},-0.32$ to -0.19$)$ (Table 1).

\section{Changes in Per Capita Visit Rates by Patient Demographics and Type of Visit}

We observed declines within demographic subgroups of sex, age, race, insurance type, and setting (Table 1). The decline was largest among adults aged $\geq 65$ years $(-0.68$ visits per person, $95 \% \mathrm{CI},-0.87$ to -0.49 ), white adults $(-0.57$ visits per person, $95 \%$ $\mathrm{CI},-0.81$ to -0.33$)$, and those in rural areas $(-0.48$ visits per person, $95 \% \mathrm{CI}$, -0.86 to -0.10$)$.

We saw declines in rates of visits for primary diagnoses including upper respiratory tract infections, urinary tract infections, joint pain, back pain, headache, and hypertension, as well as for visits to discuss lab results (Figure 1). In contrast, rates of general medical exams increased $(+0.05$ visits per person, $95 \% \mathrm{CI}, 0.03-0.07)$, as did visits for mental illness $(+0.005$ visits per person, 95\% CI, 0.001-0.01).

\section{Visit Characteristics}

The duration of primary care visits increased by 2.4 minutes per visit $(95 \%$ CI, 1.1-3.8) over the 8-year period (Table 2). On average during these visits, $P C P s$ addressed more diagnoses (+0.30 diagnoses per visit, $95 \% \mathrm{CI}, 0.16-0.43)$ and medications $(+0.82$ medications per visit,
95\% CI, 0.59-1.1). PCPs also provided more preventive services $(+0.24$ services per visit, $95 \% \mathrm{CI}, 0.12$ 0.36; Table 2, Supplemental Table 4, http://www. AnnFamMed.org/content/17/6/538/supp1/DC1) and procedures $(+0.02$ procedures per visit, $95 \% \mathrm{CI}$, 0.01 to -0.03 ; Table 2, Supplemental Table 5, http:// www.AnnFamMed.org/content/17/6/538/suppl/DC1). In a sensitivity analysis, we observed similar trends in the diagnoses and medications addressed per visit among PCPs with and without EMR capability (Supplemental Table 6, http://www.AnnFamMed.org/ content/17/6/538/suppl/DC1).

\section{Visits With Scheduled Follow-Up}

The percentage of visits with scheduled PCP follow-up declined from $62 \%$ to $57 \%(-6.0 \%, 95 \% \mathrm{CI},-12.4$ to 0.46 ; Table 3 ). This decline was largest and statistically significant among patients aged $\geq 65$ years $(-10.4 \%$, $95 \% \mathrm{CI},-15.5$ to -5.2$)$ and across patients with 1 to 5 chronic conditions, but not among younger patients or patients without a chronic condition. When examining

\section{Table 1. Annual Rate of Primary Care Visits Per Person by Patient Characteristics, 2008-2015}

\begin{tabular}{|c|c|c|c|}
\hline & $2008^{b}$ & $2015^{b}$ & $\begin{array}{l}\text { 8-Year Trend, Visits } \\
\text { per Person` }(95 \% \mathrm{CI})\end{array}$ \\
\hline Total population & 1.5 & 1.2 & $-0.25(-0.32$ to -0.19$)$ \\
\hline \multicolumn{4}{|l|}{ Sex } \\
\hline Female & 1.7 & 1.5 & $-0.29(-0.44$ to -0.13$)$ \\
\hline Male & 1.3 & 1.0 & $-0.20(-0.30$ to -0.11$)$ \\
\hline \multicolumn{4}{|l|}{ Age, y } \\
\hline $18-24$ & 0.7 & 0.6 & $-0.18(-0.26$ to -0.11$)$ \\
\hline $25-44$ & 1.0 & 0.8 & $-0.23(-0.27$ to -0.19$)$ \\
\hline $45-64$ & 1.6 & 1.4 & $-0.22(-0.32$ to -0.11$)$ \\
\hline$\geq 65$ & 2.9 & 2.2 & $-0.68(-0.87$ to -0.49$)$ \\
\hline \multicolumn{4}{|l|}{ Race } \\
\hline White & 1.6 & 1.0 & $-0.57(-0.81$ to -0.33$)$ \\
\hline Black & 1.4 & 1.3 & $-0.16(-0.44$ to 0.12$)$ \\
\hline Hispanic & 1.2 & 1.1 & $0.05(-0.25$ to 0.35$)$ \\
\hline Other & 1.2 & 1.0 & $-0.04(-0.36$ to 0.28$)$ \\
\hline \multicolumn{4}{|l|}{ Insurance type } \\
\hline Private & 1.5 & 1.1 & $-0.39(-0.48$ to -0.31$)$ \\
\hline Medicare & 2.3 & 1.8 & $-0.46(-0.59$ to -0.33$)$ \\
\hline Medicaid & 1.5 & 1.1 & $-0.37(-0.58$ to -0.16$)$ \\
\hline Other $^{\mathrm{d}}$ & 0.4 & 0.3 & $-0.09(-0.15$ to -0.02$)$ \\
\hline \multicolumn{4}{|l|}{ Practice setting } \\
\hline Metro & 1.8 & 1.5 & $-0.27(-0.43$ to -0.11$)$ \\
\hline Rural & 1.5 & 1.1 & $-0.48(-0.86$ to -0.10$)$ \\
\hline
\end{tabular}

NACMS = National Ambulatory Medical Care Survey.

avisit rate per person year calculated by dividing NAMCS visits by Current Population Survey population estimates per subgroup.

bPresented as 3-year rolling averages.

'Eight-year trend calculated for each subgroup by multiplying per year regression coefficient across study period.

'Other includes uninsured, workers' compensation, military health, and other classifications. ${ }^{40}$ 
follow-up by visit diagnosis groups, significant declines in follow-up occurred among visits addressing specific chronic illnesses and for visits to evaluate back pain, but not for visits addressing other acute conditions.

\section{Practice Capabilities}

During the study period, a rising share of PCPs reported using EMRs $(+44.3 \%, 95 \% \mathrm{CI}, 39.1-49.5)$ and offering e-mail consults $(+9.6 \%, 95 \% \mathrm{CI}, 6.1-13.3)$, secure messaging $(+60.9 \%, 95 \% \mathrm{CI}, 27.5-94.3)$, and

\section{Figure 1. Percent change in per capita visit rates by main visit diagnosis from 2008-2015.}

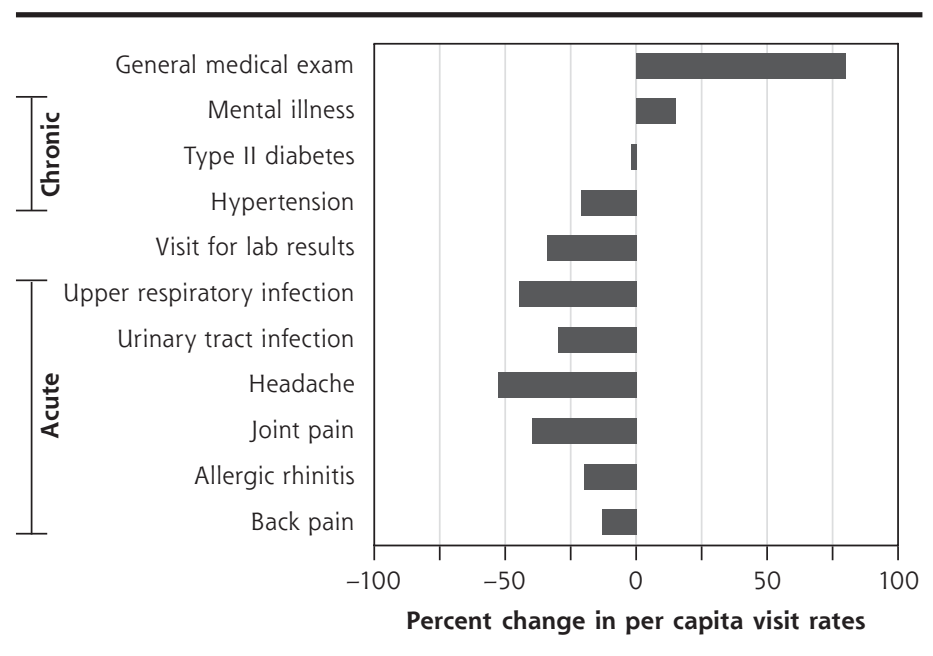

NACMS = National Ambulatory Medical Care Survey.

Visits per capita calculated by dividing NAMCS visits for each diagnosis by Current Population Survey total population estimate. Eight-year trend calculated for each subgroup by multiplying per year regression coefficient across study period. Changes were significant at $P<.05$ for all diagnoses except type 2 diabetes and allergic rhinitis.

Table 2. Visit Characteristics Per Primary Care Visit, 2008-2015

\begin{tabular}{lcccc}
\hline & 2008 $^{\mathrm{a}}$ & $\mathbf{2 0 1 5}^{\mathrm{a}}$ & $\begin{array}{c}\text { Percent } \\
\text { Change }^{\mathbf{b}}\end{array}$ & $\begin{array}{c}\text { 8-Year Trendc } \\
\mathbf{( 9 5 \% ~ C l )}\end{array}$ \\
\hline Mean visit duration, min $^{\mathrm{d}}$ & 19.3 & 21.6 & 12 & $2.4(1.1-3.8)$ \\
Mean diagnoses, No. $^{\mathrm{c}}$ & 2.0 & 2.3 & 15 & $0.30(0.16-0.43)$ \\
Mean medications, No. $^{f}$ & 3.1 & 3.9 & 26 & $0.82(0.59-1.1)$ \\
Mean preventive services, No. $^{\mathrm{g}}$ & 0.34 & 0.59 & 76 & $0.24(0.12-0.36)$ \\
Mean procedures, No. $^{\text {h }}$ & 0.06 & 0.08 & 33 & $0.02(0.01-0.03)$ \\
\hline
\end{tabular}

NACMS = National Ambulatory Medical Care Survey.

apresented as 3-year rolling averages.

bPercent change of each visit characteristic between 2008-2015.

'8-year trend calculated for each subgroup by multiplying per-year regression coefficient across study period.

dDirect time spent with physician in minutes.

eNAMCS allows up to 3 write-in ICD-9/ICD-10 visit diagnoses (see Supplemental Appendix, http://www.AnnFamMed. org/content/17/6/538/suppl/DC1).

'NAMCS allows up to 8 write-in medications.

gMean of the following 9 preventive services that were consistent in NAMCS 2007-2016: cholesterol, $A_{1 c}$ mammogram, depression screening, colonoscopy referral, bone-density, vaccines, chlamydia screening, Papanicolaou smear. ${ }^{h}$ Mean of up to 4 write-in ICD-9/ICD-10 procedures (see Supplemental Appendix, http://www.AnnFamMed.org/ content/17/6/538/suppl/DC1), based on limit from 2007-2016. after-hours appointments $(+8.6 \%, 95 \% \mathrm{CI}, 6.2-11.1)$. We found a decline in the percentage of PCPs reporting use of telephone consults $(-9.7 \%, 95 \% \mathrm{CI},-13.4$ to -6.2 ; Figure 2).

\section{DISCUSSION}

We found a substantial decline in per capita PCP visit rates that persisted among most demographic increased and PCPs addressed more issues per visit. PCPs were also more likely to report using non-face-to-face care, such as e-mail and secure messaging, and were less likely to schedule in-person primary care follow-up for some patients and conditions.

Our findings support an optimistic interpretation that the decline in primary care visits per capita may be driven in part by 2 key improvements in primary care practice. First, PCPs may be providing more comprehensive care per visit, contributing to less need for in-person follow-up. PCPs conducted longer visits and addressed more medications, diagnoses, and services such as vaccines and wound care that require in-person administration. ${ }^{19,20}$ Second, PCPs may be using more non-face-to-face care to address issues outside of in-person visits-especially given sharp declines in visit rates for lab results and low acuity issues (eg, urinary tract infection, upper respiratory infection) that may be better addressed through nonface-to-face or self-care. ${ }^{21-23}$ Visit rates for hypertension also declined, as did the percentage of hypertension visits with scheduled in-person follow-up, which may suggest a shift towards the virtual management of chronic illness. ${ }^{24}$

The primary care practice changes we highlight may be driven by both physician and patient factors. PCPs may selectively manage certain chronic and low-acuity issues through non-face-to-face care to create more time for patients who need in-person visits. ${ }^{25}$ PCPs may leverage growing EMR functionality 
to get more done during face-to-face visits: for example, providing a needed routine vaccination flagged by the EMR during an acute care visit. ${ }^{26}$ Another possibility is that patients are asking their PCPs to address more issues per visit and opting for non-faceto-face care to minimize the rising out-of-pocket costs and opportunity costs of in-person visits. ${ }^{27-29}$ Lastly, patients may feel a reduced need for scheduled follow-up, as more primary care offices incorporate same-day appointment scheduling. ${ }^{30}$

We note that the primary care visit decline may also reflect trends such as rising financial barriers and use of alternative venues. With the rise of highdeductible health plans, some may be unwilling or unable to pay out-of-pocket costs for primary care visits. ${ }^{31}$ To this end, PCPs may be billing more visits as "preventive" to reduce costs for their patients, as the Patient Protection and Affordable Care Act requires Medicare and most private plans to cover this visit type. ${ }^{5}$ For certain acute issues, adults may forego a visit to their PCP, instead choosing an urgent care or retail clinic that offers a more timely or convenient option. $^{32,33}$ The rise of office-based primary care visits by nurse practitioners and physician assistantswhich NAMCS data do not capture-may also account for a small portion of the decline. ${ }^{7,34}$ Ultimately, to understand whether this decline in visits per capita represents a positive or negative change, future work is needed to quantify how the decline affects patient outcomes.

There are several limitations to our study. First, NAMCS relies on physician self-report. However, NAMCS data, including visit duration and tests provided, have been validated in previous work. ${ }^{35,36}$ Second, NAMCS may underestimate visit complexity as physicians can only include 3 diagnoses and 8 medications with a given visit, while prior studies in primary care settings suggest that physicians regularly address more than 3 medical issues per visit. ${ }^{37}$ However, this ceiling effect would bias our result to the null, whereas we found a significant increase in diagnoses and medications per visit. Third, it is possible that our findings may be affected by changes in documentation and billing practices that may in turn contribute to a rise in physician or coder-reported diagnoses; however, our findings persisted in analyses stratified by PCP EMR status. Finally, we acknowledge that we did not directly assess other mechanisms for the decline such as unmet need due to access barriers, ${ }^{8}$ the role of nurse practitioners and physician assistants, nor how the decline affects quality of care or patient outcomes, as NAMCS visit-level data does not allow for this type of analysis.

\begin{tabular}{|c|c|c|c|}
\hline & $\begin{array}{c}2008^{\mathrm{a}} \\
\mathrm{n}=6,615^{\mathrm{b}} \\
\mathrm{n}=336,822,936^{\mathrm{c}} \\
\%\end{array}$ & $\begin{array}{c}2015^{\mathrm{a}} \\
\mathrm{n}=6,555^{\mathrm{b}} \\
\mathrm{n}=298,516,838^{\mathrm{c}} \\
\%\end{array}$ & $\begin{array}{l}\text { 8-Year Trend, } \\
\text { Percentage } \\
\text { Point Change }^{\mathrm{d}} \\
(95 \% \mathrm{Cl})\end{array}$ \\
\hline Total population & 61.9 & 56.7 & $-6.0(-12.4$ to 0.46$)$ \\
\hline \multicolumn{4}{|l|}{ Patient characteristics } \\
\hline \multicolumn{4}{|l|}{ Age, y } \\
\hline $18-24$ & 42.7 & 37.5 & $-6.0(-18.0$ to 6.9$)$ \\
\hline $25-44$ & 52.8 & 48.2 & $-5.2(-13.0$ to 2.6$)$ \\
\hline $44-64$ & 62.3 & 58.9 & $-4.2(-10.5$ to 2.1$)$ \\
\hline$\geq 65$ & 72.3 & 62.9 & $-10.4(-15.5$ to -5.2$)$ \\
\hline \multicolumn{4}{|l|}{ Chronic conditions, no } \\
\hline 0 & 45.6 & 40.3 & $-5.7(-14.9$ to 3.4$)$ \\
\hline $1-2$ & 65.3 & 57.9 & $-7.5(-13.2$ to -1.9$)$ \\
\hline $3-5$ & 75.7 & 67.3 & $-9.7(-16.7$ to -2.6$)$ \\
\hline $6-10$ & 80.5 & 71.7 & $-6.1(-12.6$ to 0.4$)$ \\
\hline \multicolumn{4}{|l|}{ Visit type } \\
\hline Preventive visit & 49.5 & 55.0 & $3.6(-5.7$ to 13.0$)$ \\
\hline \multicolumn{4}{|l|}{ Acute visitse } \\
\hline Upper respiratory infection & 38.7 & 32.8 & $-4.9(-19.0$ to 9.2$)$ \\
\hline Urinary tract infection & 43.0 & 28.0 & $-12.3(-35.4$ to 10.7$)$ \\
\hline Allergic rhinitis & 49.8 & 61.4 & $3.3(-12.8$ to 19.4$)$ \\
\hline Joint pain & 52.9 & 50.0 & $-4.2(-11.5$ to 3.1$)$ \\
\hline Back pain & 58.8 & 53.0 & $-5.3(-10.3$ to -0.4$)$ \\
\hline Headache & 53.5 & 52.1 & $-1.9(-5.1$ to 1.3$)$ \\
\hline \multicolumn{4}{|l|}{ Chronic condition visits ${ }^{\mathrm{e}}$} \\
\hline Hypertension & 82.4 & 74.0 & $-10.2(-14.1$ to -6.4$)$ \\
\hline Type 2 diabetes & 74.6 & 64.0 & $-8.3(-13.0$ to -3.6$)$ \\
\hline Mental illness & 82.0 & 76.4 & $-12.2(-18.7$ to -5.7$)$ \\
\hline \multicolumn{4}{|c|}{ NACMS = National Ambulatory Medical Care Survey. } \\
\hline $\begin{array}{l}\text { aData as 3-year rolling averages. } \\
\text { bunweighted number of NAMCS } \\
\text { 'Weighted number of NAMCS visit } \\
\text { d8-year trend calculated for each s } \\
\text { 'Diagnosis groups created by auth } \\
\text { content/17/6/538/suppl/D(1). }\end{array}$ & $\begin{array}{l}\text { its. } \\
\text { bgroup by multiplying pe } \\
\text { rs for analysis (see Supple }\end{array}$ & $\begin{array}{l}\text { regression coefficient } \\
\text { al Appendix, http://ww }\end{array}$ & $\begin{array}{l}\text { is study period. } \\
\text { nFamMed.org/ }\end{array}$ \\
\hline
\end{tabular}




\section{Figure 2. Change in the percentage of primary care physicians (PCPs) reporting practice capabilities.}

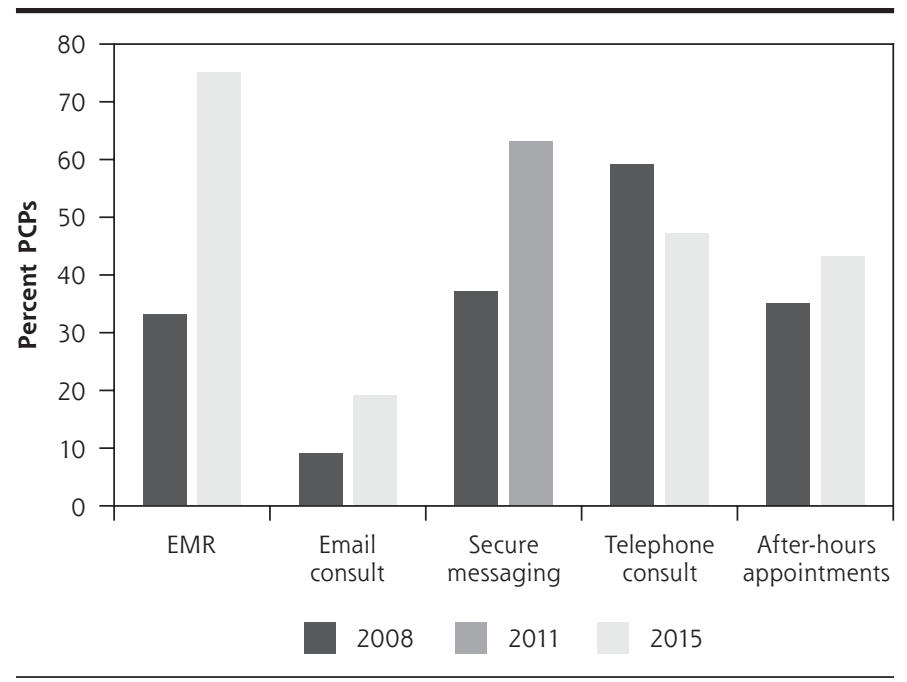

EMR = electronic medical record.

Percentage of PCPs reporting practice capabilities, 2008 vs 2015 (EMR, e-mail consult, telephone consult, after-hours appointments) and 2011 vs 2015 (secure messaging).
4. Rao A, Kale MS. Characterizing the role of the primary care provider in preventive health exams: NAMCS 2011-2014. J Gen Intern Med. 2019;34(8):1385-1387.

5. Koh HK, Sebelius KG. Promoting prevention through the Affordable Care Act. N Engl J Med. 2010;363(14): 1296-1299.

6. Chou S-C, Venkatesh AK, Trueger NS, Pitts SR. Primary care office visits for acute care dropped sharply in 2002-15, while ED visits increased modestly. Health Aff (Millwood). 2019;38(2):268-275.

7. Hargraves J, Frost A. Trends In Primary Care Visits - HCCI. https://www.healthcostinstitute.org/research/publications/hcci-research/entry/trends-in-primary-care-visits. Accessed Jun 11, 2019.

8. Ganguli I, Lee TH, Mehrotra A. Evidence and implications behind a national decline in primary care visits. J Gen Intern Med. 2019;(June):1-4.

9. Xierali IM, Hsiao C-J, Puffer JC, et al. The rise of electronic health record adoption among family physicians. Ann Fam Med. 2013;11(1):14-19.

10. Hsiao $(-J$, Hing E. Use and characteristics of electronic health record systems among office-based physician practices: United States, 2001-2012. NCHS Data Brief. 2012;(111):1-8. http://www.ncbi.nlm.nih.gov/ pubmed/23384787. Accessed Jul 26, 2019.

11. Adler-Milstein J, Huckman RS. The impact of electronic health record use on physician productivity. Am J Manag

To the degree that the decline in PCP visits per capita represents better use of office visits and nonface-to-face care, rather than unmet need, the trends we find align with the goals of new delivery models such as the patient-centered medical home and the recent Centers for Medicare and Medicaid Services Primary Care Initiative. ${ }^{14,38}$ In addition, our findings suggest the need to recognize and remunerate PCPs adequately for increasingly complex work, and mitigate the potential for PCP burnout, through strategies such as adequate reimbursement for non-visit-based care and further support of these delivery models. ${ }^{39}$

To read or post commentaries in response to this article, see it online at http://www.AnnFamMed.org/content/17/6/538.

Submitted July 28, 2019; submitted, revised, September 12, 2019; accepted September 13, 2019.

Key words: primary care visits, preventive services, National Ambulatory Medical Care Survey

Supplemental materials: Available at http://www.AnnFamMed. org/content/17/6/538/suppl/DC1/.

\section{References}

1. Starfield B, Shi L, Macinko J. Contribution of primary care to health systems and health. Milbank Q. 2005;83(3):457-502.

2. Basu S, Berkowitz SA, Phillips RL, Bitton A, Landon BE, Phillips RS. Association of primary care physician supply with population mortality in the United States, 2005-2015. JAMA Intern Med. 2019; 179(4):506-514.

3. Levine DM, Linder JA, Landon BE. The quality of outpatient care delivered to adults in the United States, 2002 to 2013. JAMA Intern Med. 2016;176(12):1778-1790. Care. 2013;19(10 Spec No):SP345-52. http://www.ncbi.nlm.nih.gov/ pubmed/24511889. Accessed Jun 29, 2019.

12. Brotzman GL, Guse CE, Fay DL, Schellhase KG, Marbella AM. Implementing an electronic medical record at a residency site: physicians' perceived effects on quality of care, documentation, and productivity. WMJ. 2009;108(2):99-103. http://www.ncbi.nlm.nih.gov/ pubmed/19437936. Accessed Jul 26, 2019.

13. Buntin MB, Jain SH, Blumenthal D. Health information technology: laying the infrastructure for national health reform. Health Aff (Millwood). 2010;29(6):1214-1219.

14. Rittenhouse DR, Shortell SM, Fisher ES. Primary care and accountable care-two essential elements of delivery-system reform. $N$ Engl J Med. 2009;361(24):2301-2303.

15. Chen C, Garrido T, Chock D, Okawa G, Liang L. The Kaiser Permanente Electronic Health Record: transforming and streamlining modalities of care. Health Aff (Millwood). 2009;28(2):323-333.

16. Barnett ML, Ray KN, Souza J, Mehrotra A. Trends in telemedicine use in a large commercially insured population, 2005-2017. JAMA. 2018;320(20):2147-2149.

17. Stafford RS, Saglam D, Causino N, et al. Trends in adult visits to primary care physicians in the United States. Arch Fam Med. 8(1): 26-32. http://www.ncbi.nlm.nih.gov/pubmed/9932068. Accessed Jul 21, 2019.

18. National Center for Health Statistics. NAMCS/NHAMCS - Reliability of Estimates. https://www.cdc.gov/nchs/ahcd/ahcd_estimation_ reliability.htm. Published 2015. Accessed Jun 12, 2019.

19. Abbo ED, Zhang Q, Zelder M, Huang ES. The increasing number of clinical items addressed during the time of adult primary care visits. J Gen Intern Med. 2008;23(12):2058-2065.

20. Bolen SD, Sage P, Perzynski AT, Stange KC. No moment wasted: the primary-care visit for adults with diabetes and low socio-economic status. Prim Health Care Res Dev. 2016;17(1):18-32.

21. White CB, Moyer CA, Stern DT, Katz SJ. A content analysis of e-mail communication between patients and their providers: patients get the message. J Am Med Inform Assoc. 2004;11(4):260-267..

22. Mehrotra A. The convenience revolution for treatment of low-acuity conditions. JAMA. 2013;310(1):35-36. 
23. Pew Research Center. Tracking for Health. https://www. pewinternet. org/2013/01/28/tracking-for-health/. Accessed Jul 26, 2019.

24. Levine DM, Dixon RF, Linder JA, Linder JA. Association of structured virtual visits for hypertension follow-up in primary care with blood pressure control and use of clinical Services. J Gen Intern Med. 2018;33(11):1862-1867.

25. Chen MA, Hollenberg JP, Michelen W, Peterson JC, Casalino LP. Patient care outside of office visits: a primary care physician time study. J Gen Intern Med. 2011;26(1):58-63.

26. Patel MS, Volpp KG, Small DS, et al. Using active choice within the electronic health record to increase influenza vaccination rates. J Gen Intern Med. 2017;32(7):790-795..

27. Ray KN, Chari AV, Engberg J, Bertolet M, Mehrotra A. Opportunity costs of ambulatory medical care in the United States. Am J Manag Care. 2015;21(8):567-574. http://www.ncbi.nlm.nih.gov/ pubmed/26295356. Accessed Jun 6, 2019.

28. Claxton G, Rae M, Long M, Damico A, Whitmore $\mathrm{H}$. Health benefits in 2018: modest growth in premiums, higher worker contributions at firms with more low-wage workers. Health Aff (Millwood). 2018;37(11):1892-1900.

29. Powell RE, Henstenburg JM, Cooper G, Hollander JE, Rising KL. Patient perceptions of telehealth primary care video visits. Ann Fam Med. 2017;15(3):225-229.

30. Murray M, Bodenheimer T, Rittenhouse D, Grumbach K. Improving timely access to primary care: case studies of the advanced access model. JAMA. 2003;289(8):1042-1046.

31. Reddy SR, Ross-Degnan D, Zaslavsky AM, Soumerai SB, Wharam JF. Impact of a high-deductible health plan on outpatient visits and associated diagnostic tests. Med Care. 2014;52(1):86-92.
32. Poon SJ, Schuur JD, Mehrotra A. Trends in visits to acute care venues for treatment of low-acuity conditions in the United States from 2008 to 2015. JAMA Intern Med. 2018;178(10):1342-1349.

33. Pitts SR, Carrier ER, Rich EC, Kellermann AL. Where Americans get acute care: increasingly, it's not at their doctor's office. Health Aff (Millwood). 2010;29(9):1620-1629.

34. Leszinsky L, Candon M. Primary care appointments for Medicaid beneficiaries with advanced practitioners. Ann Fam Med. 2019;17(4):363-366.

35. Mechanic D, McAlpine DD, Rosenthal M. Are patients' office visits with physicians getting shorter? N Engl J Med. 2001;344(3):198-204.

36. Gilchrist VJ, Stange KC, Flocke SA, McCord G, Bourguet CC. A comparison of the National Ambulatory Medical Care Survey (NAMCS) measurement approach with direct observation of outpatient visits. Med Care. 2004;42(3):276-280..

37. Goodson JD. Unintended consequences of resource-based relative value scale reimbursement. JAMA. 2007;298(19):2308-2310.

38. Centers for Medicare \& Medicaid Services. Primary Care First Model Options. https://innovation.cms.gov/initiatives/primary-carefirst-model-options/. Accessed Jul 26, 2019.

39. Dyrbye LN, West CP, Burriss TC, Shanafelt TD. Providing primary care in the United States: the work no one sees. Arch Intern Med. 2012;172(18):1420-1421.

40. Mehrotra A, Zaslavsky AM, Ayanian JZ. Preventive health examinations and preventive gynecological examinations in the United States. Arch Intern Med. 2007;167(17):1876-1883. 